\title{
The importance of stratifying ischemic risk by using the Duke score in women with ischemic heart disease and hypothyroidism before inclusion in cardiovascular rehabilitation programs
}

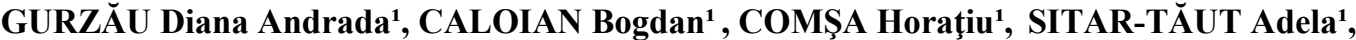 \\ ZDRENGHEA Dumitru', POP Dana ${ }^{1}$
}

Editor: Mihail HOTETEU, Romanian Association of Balneology, hoteteu@yahoo.com

Reviewers: Constantin Munteanu and Gabriela Dogaru

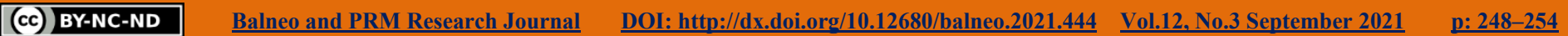

*Corresponding author: Bogdan Caloian, bogdan912@yahoo.com ;

1.“Iuliu Haţieganu” University of Medicine and Pharmacy, Cluj-Napoca, Romania

\begin{abstract}
Introduction: The relationship between abnormal thyroid function and coronary heart disease has been known for a long time, and particularly, hypothyroidism is associated with an increased risk of cardiovascular disease. The aim of this study was to evaluate the ischemic risk by using the Duke score in women with ischemic heart disease and associated hypothyroidism before inclusion in cardiovascular rehabilitation program.

Materials and methods: We included in the study 150 female patients admitted to the Cardiology Department of the Clinical Rehabilitation Hospital Cluj-Napoca. All the patients included had ischemic heart disease and performed an exercise stress testing to evaluate the effort capacity and also to stratify the ischemic risk by calculating the Duke Score. After dosing the thyroid stimulating hormone (TSH) we divided the patients in two groups: with hypothyroidism and a control group.

Results: Patients with hypothyroidism were more frequently hypertensive, $(98 \%$ vs $87 \%$, p- 0.035$)$, and they had diabetes mellitus in a higher proportion ( $51 \%$ vs $22 \%$, p- 0.005$)$. HDL cholesterol was significantly decreased in the group of patients with hypothyroidism: $40.36 \pm 10.39 \mathrm{mg} / \mathrm{dl}$ vs $44.85 \pm 10.29 \mathrm{mg} / \mathrm{dl}$ (p-0.01). Regarding the ischemic risk assessed by the Duke score, the statistically significant differences between the two groups were registered only for the category of high-risk patients, $5.55 \%$ vs $18 \%$ (p-0.048). Also, the TSH value was higher in the group with high-risk Duke score, $4.21 \pm 3.73 \mu \mathrm{IU} / \mathrm{ml}$, compared to the moderate-risk score group, $1.95 \pm 1.12 \mu \mathrm{IU} / \mathrm{ml}(\mathrm{p}-0.05)$.

Conclusion: In women with ischemic heart disease, assessing thyroid function can be useful to identify patients at high risk of ischemia. Patients with hypothyroidism tend to have a higher prevalence of cardiovascular risk factors, a higher ischemic risk objectified by the Duke score and more commonly multivascular coronary lesions. For these patients, the inclusion in cardiovascular rehabilitation programs is essential, but it is very important that the programs to be customized for each patient.
\end{abstract}

Keywords: coronary heart disease in women, exercise ECG, Duke score, ischemic risk, hypothyroidism, cardiovascular rehabilitation programs

\section{INTRODUCTION}

Mortality due to cardiovascular disease in women has significantly increased over the past years. According to the European Society of Cardiology, in 2016 it reached a proportion of $49 \%$ compared to $40 \%$ for the male sex, and of the $49 \%, 20 \%$ was due to ischemic heart disease (1-2).

However, ischemic heart disease is frequently underdiagnosed in women because of its atypical symptomatology (3). In fact, even in the presence of typical symptoms and cardiovascular risk factors, women are underevaluated, which is mainly due to the more reduced specificity of the paraclinical examinations used to assess coronary ischemic disease, particularly exercise testing (3-5). It is known that the accuracy of exercise ECG in women is lower due to a much higher percentage of false positive results, but despite this, the European 2019 Chronic Coronary Syndrome Guidelines recommends performing the exercise ECG on all patients regardless of gender, especially those who cannot be evaluated by imaging methods (1). Thus, the exercise ECG remains the most widely used method for diagnosing and evaluating ischemic heart disease worldwide $(3,7)$.

Regarding the pretest probability of ischemic coronary disease, this is higher in women with typical symptomatology and comorbidities such as hypertension, diabetes mellitus, obesity, thyroid disease (7-9). For ischemic risk stratification, the exercise stress ECG remains the only alternative when imaging methods cannot be used to estimate the risk, being recommended for patients with suspected or newly diagnosed ischemic coronary heart disease (1). The Duke score was devised to estimate survival based on the results of exercise stress testing. Furthermore, the Duke score can provide prognosis of the degree of coronary involvement $(7,10)$. Also, the latest guideline of Chronic Coronary 
Syndromes from 2019 of the European Society of Cardiology, defines the high risk of cardiovascular events in patients who were evaluated by exercise ECG test, based on the Duke score (1).

Another particularity that is frequently found in women is thyroid function impairment. The American Thyroid Association estimates that about 20 million Americans have thyroid disease, and of these, women develop it 5 to 8 times more frequently than men. Also, 1 out of 8 women will develop thyroid dysfunction during their lifetime, and especially hypothyroidism (11).

Non-diagnosis of thyroid disease is accompanied by an increase in the risk of infertility, osteoporosis, as well as cardiovascular disease (11). Thyroid dysfunction induces alterations of cardiac contractility, cardiac output, myocardial oxygen consumption, systemic vascular resistance and blood pressure (12-14).

The relationship between abnormal thyroid function and coronary disease has been known for a very long time, particularly in hypothyroidism, which is associated with hypercholesterolemia, more severe atherosclerotic lesions, hypertension and obesity $(12,14,19)$.

It is very important to include women in cardiovascular rehabilitation programs. Unfortunately, in addition to being underdiagnosed, they are generally included in a lower percentage of about $15-17 \%$ in physical training programs compared to male patients (15). Recovery in women, as in the case of men, has many advantages: it increases the effort capacityt, it contributes to the improvement of cardiovascular risk factors (decrease in lipid fractions, glycemia, blood pressure, weight loss and relief of depression) (16).

The complex evaluation of women before the actual performance of physical training is very important, especially in terms of exercise testing, but also in terms of comorbidities.

The aim of this study was to evaluate the ischemic risk in women with ischemic heart disease and associated hypothyroidism by using the Duke score.

\section{Materials and methods}

The study included 150 patients admitted to the Cardiology Department of the Clinical Rehabilitation Hospital Cluj-Napoca in 2017. All patients included in the study had ischemic heart disease, either microvascular angina or macrovascular coronary heart disease, which was defined as coronary stenosis $\geq 70 \%$ for coronary arteries and $50 \%$ in the case of the left main. The diagnosis of ischemic heart disease was established based on the exercise ECG stress testing, and subsequently by coronary angiography, which were performed according to the guidelines.

Exercise stress testing was considered positive when changes $\geq 1 \mathrm{~mm}$ in the ST segment, either horizontal or descending depression, or elevation, were recorded in the leads without pathological Q wave. Exercise testing was interrupted when malignant rhythm disorders, uncontrolled blood pressure values, ST segment changes $\geq 2 \mathrm{~mm}$ were recorded, or in the case of limiting symptoms (angina, severe dyspnea, marked fatigue). The exercise stress testing was performed using a cycle ergometer.

For each patient, the Duke score was calculated to assess the ischemic risk, and it was calculated according to the formula: duration of exercise - $(5 \mathrm{x}$ ST segment deviation $)-(4 \mathrm{x}$ angina index score $)$. The duration of exercise was measured in minutes according to the Bruce protocol, and the degree of angina was assessed and noted with 0 - no angina, 1 - no exercise-limiting angina, 2 - exercise-limiting angina. Depending on the Duke score value, the patients were classified into 3 groups: low-risk for a Duke score $\geq 5$, moderate-risk for a score between -11 and +4 , and high-risk for a score of 11 (7).

Also, the following cardiovascular risk factors were assessed: smoking status, blood pressure, lipid profile, obesity, diabetes mellitus, thyroid function by thyroid stimulating hormone (TSH) measurement (the reference TSH value being $0.4-4 \mu \mathrm{IU} / \mathrm{ml}$ ). The free thyroxine (FT4) fraction was only measured when TSH levels were changed, despite a well known thyroid disease; thus, due to the reduced number of determinations, no correlations depending on FT4 were made.

The patients were assigned to 2 groups. The first group was formed by patients without associated thyroid involvement - 109 (72.7\%), and the second group included patients with associated hypothyroidism - 41 $(27.3 \%)$.

Statistical analysis was performed with SPSS 16.0 and MedCalc software (v 10.3.0.0, MedCalc Software, Ostend, Belgium). Using descriptive analysis, the clinical and demographic characteristics of the patients included in the study were presented. For a numerical variable for normal distribution evaluation - use of Kolmogorov test - depending on care, and for the application of parametric/non-parametric tests - the mean \pm standard deviation and median were used. The differences and correlations between quantitative variables were assessed using Student/Mann Whitney/ANOVA tests, and Pearson/Spearman correlation coefficients, respectively. A $p$ value $<0.05$ was considered statistically significant. Ethics. The present clinical study was approved by the local Ethics Committee (approval number 2606/4.04.2018) and was performed in accordance with the ethical standards laid down in the 1964 Declaration of Helsinki and its later amendments. All patients included in the present study gave their informed consent.

\section{Results}

The general characteristics of the patients are synthesized in table 1. Regarding the distribution of cardiovascular risk factors, there were no significant differences between 
the two groups for smoking ( $27 \%$ vs $12 \%)$, dyslipidemia (total cholesterol $185.46 \pm 48.88 \mathrm{mg} / \mathrm{dl} \quad$ vs $184.36 \pm 51.18 \mathrm{mg} / \mathrm{dl}$, LDL cholesterol $107.65 \pm 42.69 \mathrm{mg} / \mathrm{dl}$ vs $111.20 \pm 45.27 \mathrm{mg} / \mathrm{dl}$, triglycerides $163.94 \pm 92.92 \mathrm{mg} / \mathrm{dl}$ vs $171.90 \pm 103.3 \mathrm{mg} / \mathrm{dl})$ and obesity ( $70 \%$ vs $82 \%)$.

In contrast, patients with hypothyroidism were more frequently hypertensive, $98 \%$ compared to $87 \%$ for those without thyroid dysfunction (p-0.035), and they also had diabetes mellitus in a higher proportion: $51 \%$ vs $22 \%$ (p$0.005)$. HDL cholesterol was statistically significantly decreased in the group of patients with associated hypothyroidism: $40.36 \pm 10.39 \mathrm{mg} / \mathrm{dl}$ vs $44.85 \pm 10.29$ $\mathrm{mg} / \mathrm{dl}(\mathrm{p}-0.01)$.

There were no significant differences regarding the mean age of patients with associated hypothyroidism compared to those without thyroid involvement, $65.02 \pm 9.34$ vs $62.57 \pm 10.32$ (p-ns). Also, the exercise capacity assessed by the number of METs (metabolic equivalent) recorded during the exercise stress testing, did not show statistically significant differences between the two groups, $5.49 \pm 1.72$ vs $5.71 \pm 0.91$ (p-ns).

In general, the patients included in the study had microvascular angina in a significantly higher proportion, $66.66 \%$ compared to only $33.33 \%$ with significant coronary lesions described by angiography $(p=0.036)$, differences that also occurred when we compared the type of coronary heart disease according to the two groups. The results are summarized in table 1.

Table 1. General characteristics of the patients included in the study

\begin{tabular}{|c|c|c|c|}
\hline & $\begin{array}{l}\text { Group 1 } \\
\text { Without } \\
\text { thyroid } \\
\text { disease } \\
\end{array}$ & $\begin{array}{l}\text { Group } 2 \\
\text { With } \\
\text { hypothyroidism }\end{array}$ & $P$ value \\
\hline Age & $62.57 \pm 10.32$ & $65.02 \pm 9.34$ & $p-n s$ \\
\hline Smoking & $27 \%$ & $12 \%$ & $p-n s$ \\
\hline $\begin{array}{l}\text { Total } \\
\text { cholesterol }\end{array}$ & $\begin{array}{l}185.46 \pm 48.8 \\
8 \mathrm{mg} / \mathrm{dl}\end{array}$ & $\begin{array}{l}184.36 \pm 51.18 \mathrm{mg} \\
/ \mathrm{dl}\end{array}$ & p- ns \\
\hline $\begin{array}{l}\text { LDL } \\
\text { cholesterol }\end{array}$ & $\begin{array}{l}107.65 \pm 42.6 \\
9 \mathrm{mg} / \mathrm{dl}\end{array}$ & $\begin{array}{l}111 \pm 45.27 \mathrm{mg} / \\
\text { dl }\end{array}$ & p- ns \\
\hline Triglycerides & $\begin{array}{l}163.94 \pm 92.9 \\
2 \mathrm{mg} / \mathrm{l}\end{array}$ & $\begin{array}{l}171.90 \pm 103.3 \mathrm{mg} \\
/ \mathrm{dl}\end{array}$ & p- ns \\
\hline $\begin{array}{l}\text { HDL } \\
\text { cholesterol }\end{array}$ & $\begin{array}{l}44.85 \pm 10.29 \\
\mathrm{mg} / \mathrm{d}\end{array}$ & $\begin{array}{l}40.36 \pm 10.39 \mathrm{mg} / \\
\text { dl }\end{array}$ & $p=0.01$ \\
\hline Obesity & $70 \%$ & $80 \%$ & p- ns \\
\hline Hypertension & $87 \%$ & $98 \%$ & $\mathrm{p}=0.035$ \\
\hline $\begin{array}{l}\text { Diabetes } \\
\text { mellitus }\end{array}$ & $22 \%$ & $51 \%$ & $p=0.005$ \\
\hline $\begin{array}{l}\text { Microvascular } \\
\text { angina }\end{array}$ & $74(67.88)$ & $26(32.2 \%)$ & $p=0.032$ \\
\hline $\begin{array}{l}\text { Macrovascular } \\
\text { ischemic heart } \\
\text { disease }\end{array}$ & $35(63.41)$ & $15(36.59 \%)$ & $p=0.040$ \\
\hline $\begin{array}{l}\text { Mean Duke } \\
\text { score value }\end{array}$ & $5.12 \pm 4.05$ & $7.10 \pm 4.39$ & $\mathbf{p}-\mathbf{n s}$ \\
\hline $\begin{array}{l}\text { Number of } \\
\text { METs }\end{array}$ & $5.49 \pm 1.72$ & $5.71 \pm 0.91$ & p- ns \\
\hline
\end{tabular}

In the group of patients with hypothyroidism and macrovascular coronary lesions, the majority, $60 \%$, had trivascular lesions, $26.66 \%$ had bivascular lesions, and $13.33 \%$ had univascular coronary lesions, while in the group with normal thyroid function $42.85 \%$ had trivascular lesions, $28.57 \%$ had bivascular and also univascular coronary lesions. (Fig. 1)

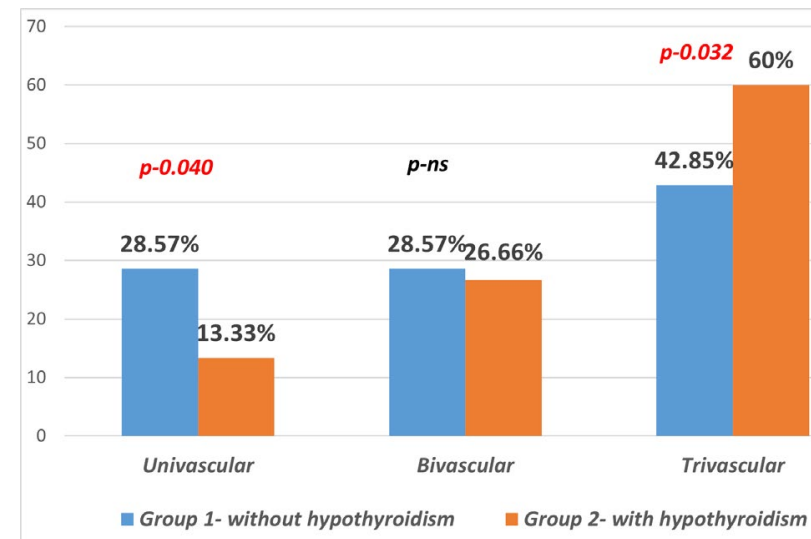

Figure 1. The magnitude of macrovascular coronary impairment depending on the associated hypothyroidism

The mean Duke score value was $5.5881 \pm 4.179$, with recorded values between -13.1600 and +9.3700 . There were no statistically significant differences in the Duke score values between the two groups $(5.12 \pm 4.05$ vs $7.10 \pm 4.39$, p-ns).

From the point of view of ischemic risk assessed based on the Duke score, we divided the patients into the three risk categories, low-risk, moderate-risk and high-risk. Analyzing the differences between the two groups, according to the Duke score risk category, we obtained a statisticallu significant difference but only for the highrisk category $5.55 \%$ vs $18 \%$ (p-0.048), in contrast with the moderate-risk category $(91.9 \%$ vs $80.6 \%, \mathrm{p}-\mathrm{ns})$ and low-risk category (2.6\% vs $1.4 \%$, p-ns). (Table 2 )

Table 2. Ischemic risk assessed depending on the Duke score value

\begin{tabular}{|l|l|l|l|}
\hline Duke score & $\begin{array}{l}\text { Group 1 } \\
\text { Without } \\
\text { thyroid disease }\end{array}$ & $\begin{array}{l}\text { Group 2 } \\
\text { With } \\
\text { hypothyroidism }\end{array}$ & P value \\
\hline Low risk & $\mathbf{2 . 6 \%}$ & $\mathbf{1 . 4 \%}$ & p-ns \\
\hline $\begin{array}{l}\text { Moderate } \\
\text { risk }\end{array}$ & $\mathbf{9 1 . 9 \%}$ & $\mathbf{8 0 . 6 \%}$ & p-ns \\
\hline High risk & $\mathbf{5 . 5 5 \%}$ & $\mathbf{1 8 \%}$ & $p-0.048$ \\
\hline
\end{tabular}

In general, the mean TSH value did not show significant differences between women with microvascular angina and those with macrovascular coronary lesions, except when this was correlated with the Duke score value, the TSH value being higher in the group with high-risk Duke score, $4.21 \pm 3.73 \mu \mathrm{IU} / \mathrm{ml}$, compared to the moderate-risk score group, $1.95 \pm 1.12 \mu \mathrm{IU} / \mathrm{ml}$ (p-0.05) (Fig. 2). 


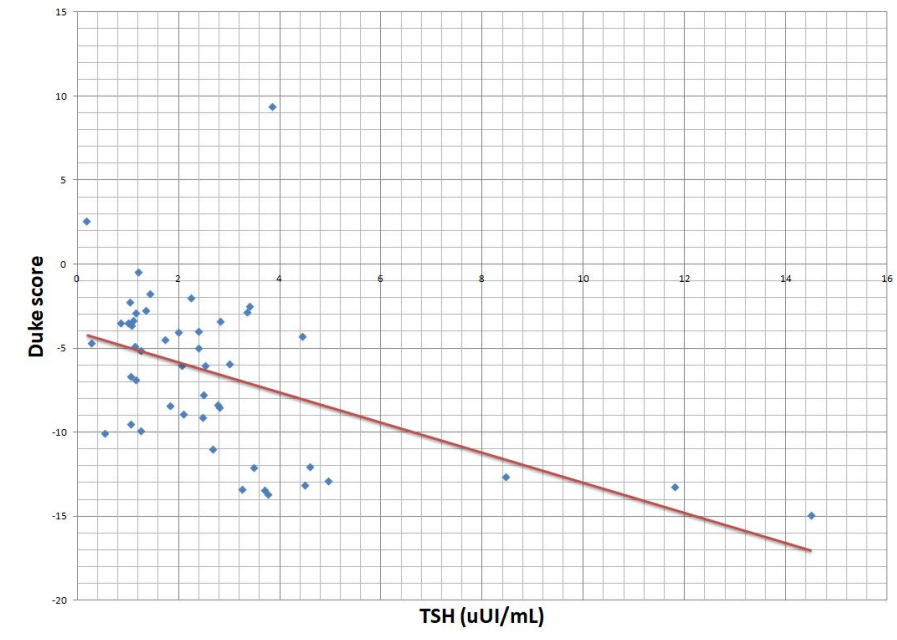

Figure 2. The relationship between the severity of hypothyroidism and ischemic risk. Increased TSH values are correlated with a high risk Duke score.

Most of the patients with associated hypothyroidism, respectively $85.36 \%$ were on hormone replacement therapy. The remaining $14.63 \%$ of patients were patients with newly diagnosed hypothyroidism, so patients in whom thyroid replacement therapy has not yet been prescribed.

When we analyzed patients with hypothyroidism and high-risk Duke score, we noticed that no patient in this category had received thyroid replacement therapy. In contrast, the highest proportion of patients with hypothyroidism undergoing thyroid replacement therapy, $77.15 \%$, were in the category of patients with a low-risk Duke score. The rest of patients $22.85 \%$, on treatment for thyroid hypofunction, were assigned to the moderate-risk category of Duke score.

\section{Discussions}

It is well known that women are cardiologically underevaluated and underdiagnosed, because pain is most frequently atypical, only $29.7 \%$ of all women complaining of typical angina pain $(3,6)$.

Many studies have demonstrated that women present to the emergency service much later, after the cardiac lesions have developed, precisely due to atypical symptoms. Under these circumstances, women who present to emergency departments are likely to be investigated less rigorously, which delays both diagnosis and treatment administration. Also, women diagnosed with coronary disease benefit to a lesser extent from noninvasive or invasive diagnostic methods, as well as from adequate treatment methods $(3,6,18)$.

Thus, the exercise stress testing is used in a lower proportion compared to male patients, even in the presence of risk factors and typical symptomatology, consequently in the case of a high-risk class. One of the reasons why exercise testing is less used in women is the higher number of false positive results recorded among them. The explanation for these false positive results is the angiographic result with normal coronary arteries, but let's not forget that these results come from older studies, in which coronary microvascular circulation was not tested, microvascular angina being a relatively new entity and more common in women. However, only a quarter of the women who have not performed an exercise test are investigated by other diagnostic methods (3,7-9). Nevertheless, the exercise test remains the most widely used diagnostic method for ischemic heart disease, and even if the sensitivity and specificity is lower in women compared to men, the ESC guideline for chronic coronary syndrome it's not making a difference between sex and recommends the exercise ECG as a first class indication, especially in those who cannot be evaluated throught imaging methods (1). However, the exercise test has proved to have a high predictive value in women with a low pretest probability of coronary disease (7-9). At the same time, exercise testing is essential and mandatory even before the inclusion of patients in cardiovascular rehabilitation programs. In this regard, the exercise test provides useful information regarding the calculation of submaximal heart rate, ischemic and arrhythmic risk (17). Thus, given the less specific ECG changes in women, other parameters can guide the interpretation of the subsequent exercise test and therapeutic approach, one of these parameters being the Duke score. This has proved to be highly predictive for diagnosing ischemic heart disease in women, with a higher specificity in women than in men $(7,8,19)$.

Studies show that patients with a high-risk Duke score have a 376 times higher probability to have significant coronary stenosis compared to those with a low-risk Duke score $(8,20)$. Also regarding the Duke score risk class in women with ischemic heart disease, those who were assigned to the high-risk class had more significant lesions, at least one lesion of $75 \%$, or had multivascular lesions $(9,20)$. Thus, the Duke score provides accurate information regarding diagnosis and prognosis in the assessment of patients with a clinical suspicion of ischemic heart disease (21).

So far, studies evaluating the importance of the Duke score in women have been mainly comparative, between men and women, while no study examines the importance of the Duke score for stratification of ischemic risk in women with ischemic heart disease and other comorbidities, such as hypothyroidism, a pathology which is associated with an increased cardiovascular risk. The association between ischemic heart disease and hypothyroidism has been known for a very long time. Thyroid hormones have the ability to alter smooth vascular cells and endothelial vascular function, with an important role particularly in the case of hypothyroidism, where arterial compliance is reduced; subsequently, there 
is an increase in vascular resistance with the development of arterial hypertension (13,22-25). Excessive hypothyroidism is characterized by a significant increase in LDL cholesterol and hypercholesterolemia, but these alterations of the lipid profile are reversible with thyroid hormone replacement therapy (25). These changes secondary to hypothyroidism, ie hypertension, especially through an increase in the diastolic blood pressure value, and dyslipidemia, lead to an acceleration of the atherosclerotic process and increased the risk for ischemic heart disease $(23,24)$.

In the myocardium, thyroid hormones influence both diastolic relaxation and contractile function, with a proangiogenic effect and an important role in the maintenance of extracellular matrix homeostasis. Endothelial function is also affected, particularly in hypothyroidism, through a decrease in vascular smooth muscle relaxation mediated by nitric oxide. The low T3 (triiodothyronine) level increases oxidative stress and apoptosis, which lead to a worsening of the ventricular function (12,24-26). It has been proved that in postmyocardial infarction patients, thyroid hormones influence the left ventricular structure, geometry and function (27). Other studies have shown that in patients with STEMI (ST-Elevation Myocardial Infarction) and associated thyroid disease, there is a 3.5-fold higher risk of complications such as cardiogenic shock or even death, compared to patients with STEMI without associated thyroid pathology (12,28-29). In fact, the association of a reduced level of thyroid hormones should be considered a cardiovascular risk factor.

In our study, there were no significant differences between the two groups regarding the values of total cholesterol, LDL cholesterol and triglycerides, while the majority of the included patients had a mild form of thyroid hormone imbalance. This finding is in accordance with the literature studies, which report a slight increase in lipid fractions for patients with mild thyroid dysfunction, but not for those with moderate or severe thyroid hormone imbalance (30-31).

HDL cholesterol was significantly decreased in the second group, which included patients with hypothyroidism. In addition to the well known effect of thyroid hormones on LDL cholesterol metabolism, some studies have also demonstrated their influence on HDL cholesterol metabolism. Thyroid hormones influence the metabolism of HDL cholesterol through their effect on hepatic lipase (HL) (31). Certainly, there are studies that correlate hypothyroidism with extremely low plasma HDL cholesterol levels and extensive atherosclerotic plaques (32).

In the current study, in patients with hypothyroidism, hypertension was present in a higher proportion than in those without this disease. Both hypothyroidism and hyperthyroidism can increase the risk of arterial hypertension, but this is present in a much higher percentage in the case of patients with hypothyroid status (33). Arterial stiffness is higher in hyperthyroidism, especially due to the effect of thyroxine on the endothelium and vascular smooth muscles, mediated by ion channels and nitric oxide (35). Also, calcium/calmodulin-dependent protein kinase IV (CaMKIV) plays an important role in regulating blood pressure by controlling the activity of endothelial nitric oxide synthase (eNOS) $(33,34)$.

The hemodynamic effects of hypothyroidism are opposite to those found in hyperthyroidism, although clinical manifestations are less obvious, bradycardia being the most frequent sign, along with hypertension (33). Patients with hypothyroidism have more reduced renin release, with higher secondary sensitivity to salt consumption; thus, renal reabsorption leads to a $5.5 \%$ increase in blood volume. About $30 \%$ of patients with hypothyroidism have increased diastolic blood pressure values $(13,33)$. Also, in hypothyroidism there are important changes in lipid metabolism, with hypercholesterolemia, changes in the carotid intima-media thickness, peripheral vascular resistance, all of which increase the incidence of hypertension and aggravate hypothyroidism. Under these circumstances, a vicious circle is created, with blood pressure worsening (33). Our study confirms the previously mentioned data, arterial hypertension being found in a higher proportion in the group of patients with hypothyroidism.

The high ischemic risk and multivascular lesions in patients with diabetes mellitus are well known. At the same time, the close interrelation between diabetes mellitus and thyroid disease is equally well known; both hypothyroidism and hyperthyroidism have proved to be frequently associated with diabetes mellitus $(36,37)$. The American Thyroid Association Guidelines recommend even more frequent testing of thyroid function in patients with diabetes mellitus (39). A meta-analysis reported that about $11 \%$ of patients with diabetes mellitus had associated thyroid disease, with a higher prevalence among female patients (38).

The pathophysiological mechanisms are complex, involving genetic changes, carbohydrate metabolic changes, all these factors contributing to insulin resistance (38). The current study confirms the literature data. Patients in the second group, with associated thyroid disease, had in a higher proportion associated diabetes mellitus compared to those without thyroid involvement.

A study conducted in Shanghai on 1799 patients demonstrated that TSH and FT4 levels were associated with ischemic coronary disease, and also with the severity of atherosclerotic lesions, an association that became insignificant after adjustment of free FT4 values (25). However, this study did not demonstrate an 
association of thyroid function with euthyroidism and ischemic coronary disease.

Consequently, the association of a thyroid dysfunction places the patient in a high cardiovascular risk category. Therefore, the Duke score should also have a higher sensitivity and specificity in this category of patients.

Nevertheless, in our study there were no significant differences in the Duke score between patients with and without associated hypothyroidism. From the point of view of ischemic risk assessed based on the Duke score, there were significant differences between the two groups only for the high-risk Duke score category, not for the moderate-risk category. In general, there were no significant correlations between the TSH value and the Duke score, except for patients with a high-risk Duke score, in which the TSH value was higher in the case of hypothyroidism compared to no thyroid involvement.

This study confirms the conclusions of other studies related to the reduction of the severity of ischemic risk and atherosclerosis after thyroid dysfunction correction, especially in patients with hypothyroidism. In our study, patients with a high-risk Duke score were those without any thyroid replacement therapy, while the majority of patients on endocrine treatment were assigned to the lowrisk Duke score class. This confirms the hypothesis that thyroid function correction reduces ischemic risk and consequently, improves the long-term prognosis of patients (25).

\section{Conclusions}

In conclusion, in women with ischemic heart disease, assessing thyroid function can be useful to identify patients at high risk of ischemia, risk assessed by calculating the Duke score based on the result of the exercise ECG stress testing. Also, in patients with macrovascular coronary involvement, associated thyroid disease and a high-risk Duke score tend to lead to multivascular coronary involvement, with a poorer prognosis. At the same time, the absence of treatment for thyroid disease is associated with a high-risk Duke score, which obviously entails a higher ischemic risk. Ischemic risk assessment in this category of patients is extremely useful especially when they are following a physical training program.

Further studies including a much greater number of patients with ischemic heart disease and associated hypothyroidis are required to confirm the results obtained in our study.

\section{Acknowledgments}

We would like to thank all the participants in the study.

\section{References :}

1. Knuuti J, Wijns W, Saraste A, et al. ESC Scientific Document Group, 2019 ESC Guidelines for the diagnosis and management of chronic coronary syndromes: The Task
Force for the diagnosis and management of chronic coronary syndromes of the European Society of Cardiology (ESC), European Heart Journal .2019;00:1-71.

2. Fihn SD, Gardin JM, Abrams J, Berra K, Blankenship JC. 2012 ACCF/AHA/ACP/AATS/PCNA/SCAI/STS Guideline for the Diagnosis and Management of Patients With Stable Ischemic Heart Disease. J Am Coll Cardiol. 2012; 60(24):e44-e164.

3. Pop D, Sitar-Taut A, Zdrenghea D. Cardiopatia ischemică. In: Mitu F, Pop D, Zdrenghea D. Particularităţi ale patologiei cardiovasculare la femei. Editura Pim. Iaşi. 2012; 87-110.

4. Reynolds HR, Srichai MB, Iqbal SN, et al. Mechanisms of myocardial infarction in women without angiographically obstructive coronary artery disease. Circulation. 2011;124:1414-1425.

5. Sheps DS, Kaufmann PG, Sheffield D, et al. Sex differences in chest pain in patients with documented coronary artery disease and exercise induced ischemia: results from the PIMI study. Am Heart J. 2001;142:864871 .

6. Zdrenghea D, Pop D. Testarea de efort în practica medicală. Ed. Clusium, Cluj-Napoca. 2012.

7. Kohli P, Gulati M. Exercise stress testing in women: going back to the basics. Circulation. 2010; 122:2570-80.

8. Alexander KP, Shaw LJ, Shaw LK, Delong ER, Mark DB, Peterson ED. Value of exercise treadmill testing in women. J Am Coll Cardiol. 1998; 32:1657-64.

9. Gulati M, Arnsdorf MF, Shaw LJ, et al. Prognostic value of the duke treadmill score in asymptomatic women. Am J Cardiol. 2005; 96:369-75.

10.89th Annual Meeting of the American Thyroid Association; 2019. Available from: https://www.thyroid.org/mediamain/press-room/. Accesed October 11, 2019.

11. von Hafe M, Neves JS, Vale C, Borges-Canha M, LeiteMoreira A. The impact of thyroid hormone dysfunction on ischemic heart disease. Endocr Connect. 2019; 8(5):R76R90.

12. Klein I, Danzi S. Thyroid disease and the heart. Current Problems in Cardiology. 2016; (41):65-92. (10.1016/j.cpcardiol.2015.04.002).

13. Razvi S, Jabbar A, Pingitore A, et al. Thyroid hormones and cardiovascular function and diseases. Journal of the American College of Cardiology. 2018; 71:1781-1796.

14. Skolnick AH, Alexander KP, Chen AY, Roe MT, Pollack CV Jr. Characteristics, management, and outcomes of 5,557 patients age $>$ or $=90$ years with acute coronary syndromes: results from the CRUSADE Initiative. J Am Coll Cardiol. 2007; 49(17):1790-7.

15. Williams RI, Fraser AG, Westr R. Gender differences in management after acute myocardial infarction: not "sexism" but a reflexion of age atpresentation. J Public Health 2004;26:259-635; Marques Vidal P, Cambou JP, Ferrieres J, Thomas D, Grenier O, et al. Distribution et prise en charge des facteurs de risque cardiovasculaires chez des patients coronariens : étude Prévenir. Arch Mal Coeur 2001;94: 673-80.

16. Menezes AR, Lavie CJ, Milani RV, Forman DE, King M, Williams MA. Cardiac rehabilitation in the United States. Prog Cardiovasc Dis 2014;56:522-529 Midence L, Arthur HM, Oh P, Stewart DE, Grace SL. Women's Health 
Behaviours and Psychosocial Well-Being by Cardiac Rehabilitation Program Model: A Randomized Controlled Trial. Can J Cardiol. 2016;32(8):956-62.

17. Andreotti F, Marchese N. Women and coronary heart disease. Heart 2008; 94: 108-116.

18. Daly C, Clemens F, Lopez Sendon JL, et al. EURO HEART SURVEY INVESTIGATORS. Gender differences in the management and clinical outcome of stable angina. Circulation. 2006; 113: 490-498.

19. Dădârlat A, Zdrenghea D, Pop D. Role of Duke treadmill score in the diagnosis of ischemic heart disease in women. Rom J Intern Med. 2015; 53(2):146-52.

20. Shaw LJ, Peterson ED, Shaw LK, et al. Use of a prognostic treadmill score in identifying diagnostic coronary disease subgroups. Circulation.1998;98(16):1622-30.

21. Cappola AR, Ladenson PW. Hypothyroidism and atherosclerosis. The Journal of Clinical Endocrinology \& Metabolism. 2003;88(6):2438-2444.

22. Hyland KA, Arnold AM, Lee JS, Cappola AR. Persistent subclinical hypothyroidism and cardiovascular risk in the elderly: the cardiovascular health study. The Journal of Clinical Endocrinology and Metabolism. 2013;98(2):533540 .

23. Åsvold BO, Bjøro T, Platou C, Vatten LJ. Thyroid function and the risk of coronary heart disease: 12-year follow-up of the HUNT Study in Norway. Clinical Endocrinology. 2012;77(6):911-917.

24. Ling Y, Jiang J, Gui M, et al. Thyroid Function, Prevalent Coronary Heart Disease, and Severity of Coronary Atherosclerosis in Patients Undergoing Coronary Angiography. Int J Endocrinol. 2015; 82:70-72.

25. Jabbar A, Razvi S, Pingitore A, et al. Thyroid Hormones and Cardiovascular Function and Diseases. Journal of the American College of Cardiology. 2018; 71(16):1781-1797.

26. Elizabeth N. Pearce, Qiong Yang, Emelia J. Benjamin, et al. Thyroid Function and Left Ventricular Structure and Function in the Framingham Heart Study. Thyroid. 2010 Apr; 20(4): 369-373.

27. Franklyn JA, Gammage MD, Ramsden DB, Sheppard MC. Thyroid status in patients after acute myocardial infarction. Clinical Science 1984; 67:585-590.

28. Ozcan KS, Osmonov D, Toprak E, et al. Sick euthyroid syndrome is associated with poor prognosis in patients with ST segment elevation myocardial infarction undergoing primary percutaneous intervention. Cardiology Journal 2014;21:238-244.

29. Duntas LH. Thyroid disease and lipids. Thyroid. 2002;12(4):287-93

30. Rizos CV, Elisaf MS, Liberopoulos EN. Effects of Thyroid Dysfunction on Lipid Profile. Open Cardiovasc Med J. 2011; 5: 76-84.

31. Tan KCB, Shiu SWM, Kung AWC. Effect of Thyroid Dysfunction on High-Density Lipoprotein Subfraction Metabolism: Roles of Hepatic Lipase and Cholesteryl Ester Transfer Protein. The Journal of Clinical Endocrinology \& Metabolism. 1998; 83(8):2921-2924.

32. Carantoni M, Vigna GB, Stucci N, Zanca R, Fellin R.Low levels of HDL cholesterol in hypothyroid patients with cardiovascular diseases. Minerva Endocrinol. 1997 ;22(4):91-7.
33. Berta E, Lengyel I, Halmi S, et al. Hypertension in Thyroid Disorders. Front Endocrinol (Lausanne). 2019; 10: 482.

34. Santulli G, Cipolletta E, Sorriento D, et al. CaMK4 gene deletion induces hypertension. J Am Heart Assoc. 2012; $1: \mathrm{e} 001081$.

35. Levy D, Larson MG, Benjamin EJ, et al. Framingham Heart Study 100K Project: genome-wide associations for blood pressure and arterial stiffness. BMC Med Genet. 2007; 8:S3.

36. Amit S, Kapoor A, Tiwari AR, et al. Effect of levothyroxine therapy on hypertension in hypothyroid patients. Internet Journal of Medical Update .2012;7(1):138.

37. Brenta G, Danzi S, Klein I. Potential therapeutic applications of thyroid hormone analogs. Nature Clinical Practice Endocrinology and Metabolism. 2007;3(9):632640

38. Kadiyala R, Peter R, Okosieme OE. Thyroid dysfunction in patients with diabetes: clinical implications and screening strategies. International Journal of Clinical Practice. 2010;64(8):1130-1139. 